Supporting Information For:

\title{
Isolated Effects of Surface Ligand Density on the Catalytic Activity and Selectivity of Palladium Nanoparticles
}

\author{
Kevin M. Vargas, ${ }^{1,2}$ Khin Aye San, ${ }^{1}$ and Young-Seok Shon ${ }^{1,2, *}$ \\ ${ }^{I}$ Department of Chemistry and Biochemistry and ${ }^{2}$ Keck Energy Materials Program, California \\ State University Long Beach, 1250 Bellflower Boulevard, Long Beach, California 90840, United \\ States
}

*For correspondence: Email: ys.shon@csulb.edu.Phone: 562-985-4466. Fax: 562-985-8547.

I. ${ }^{1} \mathrm{H}$ NMR Characterization of Sodium S-Dodecanethiosulfate Ligand

II. Characterization of C8-PdNP Synthesized via Reversed Alkyl Thiosulfate Addition Method TEM Images of C8-PdNPs

III. Characterization of C12-PdNPs Synthesized via Reversed Alkyl Thiosulfate Addition Method

${ }^{1} \mathrm{H}$ NMR Characterization of C12-PdNPs Synthesized via Reversed Method

ICP-AES Characterization of C12-PdNPs Synthesized via Reversed Method

IV. ${ }^{1} \mathrm{H}$ NMR Analysis of PdNP Catalytic Kinetic Study Assays

Styrene Catalysis ${ }^{1} \mathrm{H}$ NMR Spectra

Pent-1-ene Catalysis ${ }^{1} \mathrm{H}$ NMR Spectra

2,3-Dimethylbuta-1,3-diene Catalysis ${ }^{1} \mathrm{H}$ NMR Spectra

V. Catalytic Conversion Graphs

VI. Fractionation Data

VII. Recycle Study Data 


\section{I. ${ }^{1} \mathrm{H}$ NMR Characterization of Sodium S-Dodecanethiosulfate Ligand}

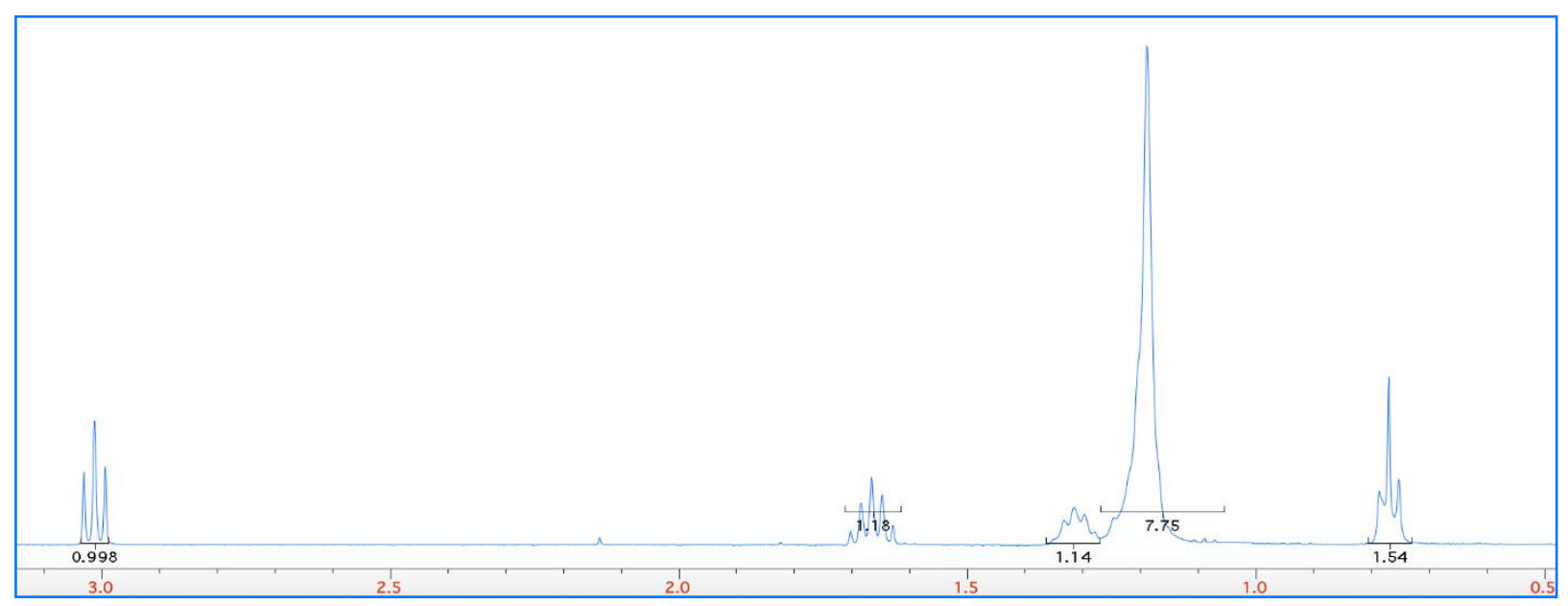

Figure S1. ${ }^{1} \mathrm{H}$ NMR spectrum of sodium S-dodecanethiosulfate ligand. 


\section{Characterization of C8-PdNPs Synthesized via Reversed Alkyl Thiosulfate Addition Method}
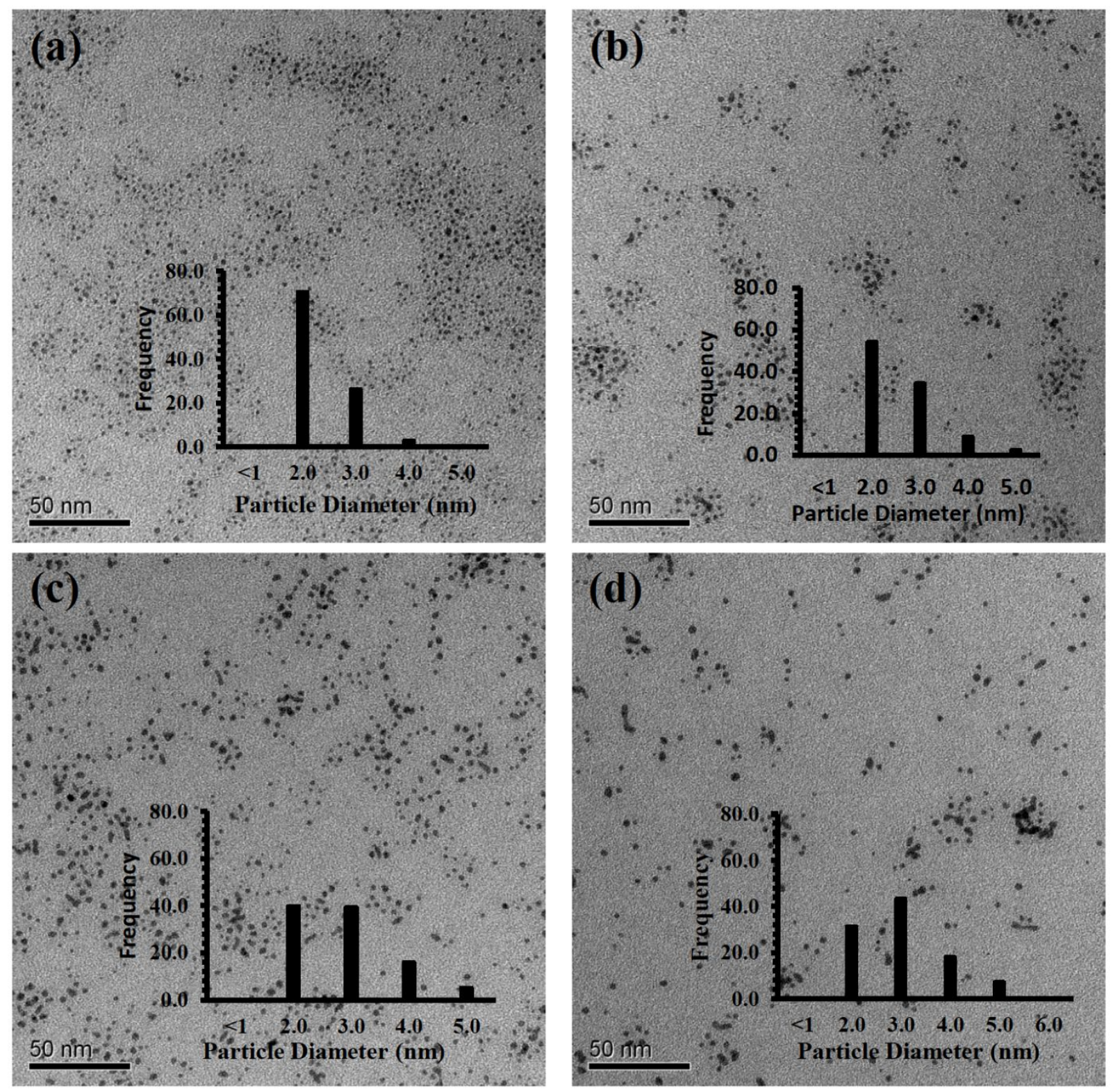

Figure S2. TEM images and size distribution histograms (a)-(d) for PdNPs in Table 1 (1-4) respectively. 

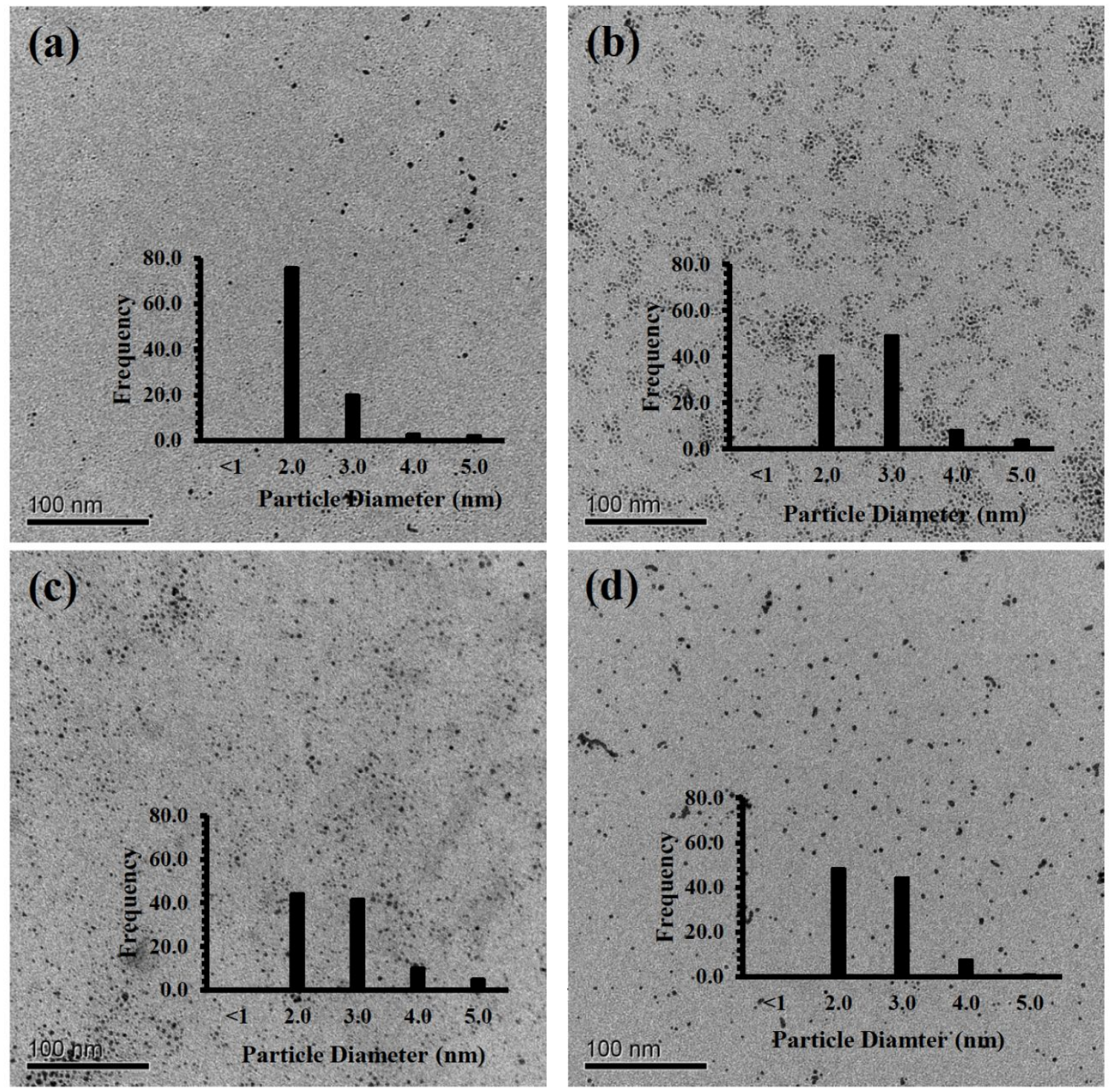

Figure S3. TEM images and size distribution histograms (a)-(d) for PdNPs in Table 1 (9-12) respectively. 


\section{Characterization of C12-PdNPs Synthesized via Reversed Alkyl Thiosulfate Addition Method}
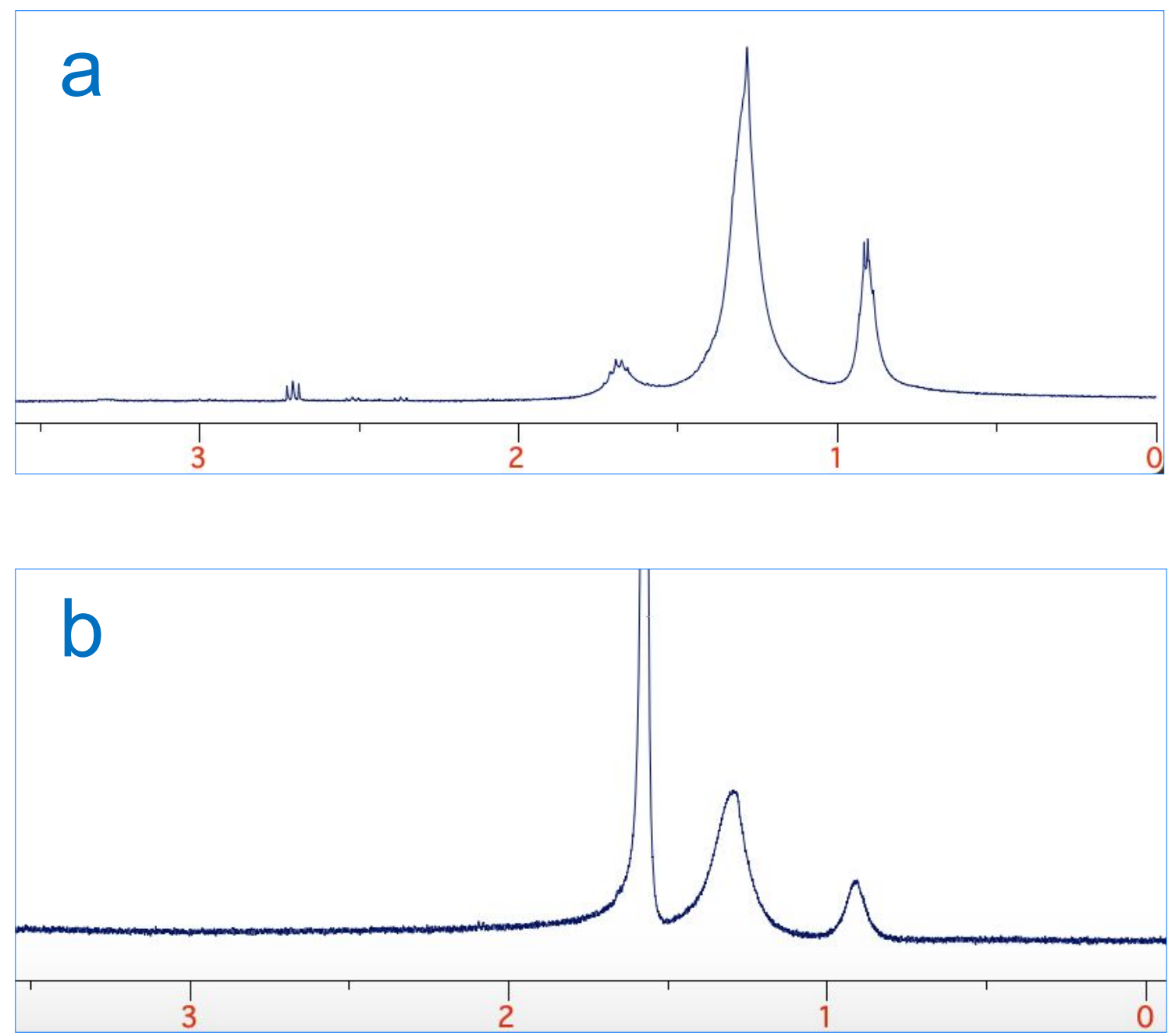

Figure S4. Representative ${ }^{1} \mathrm{H}$ NMR characterization of C12-PdNP synthesized via reversed method. a) Initial spectrum of PdNPs with impurities, b) spectrum of PdNPs after additional washing. 

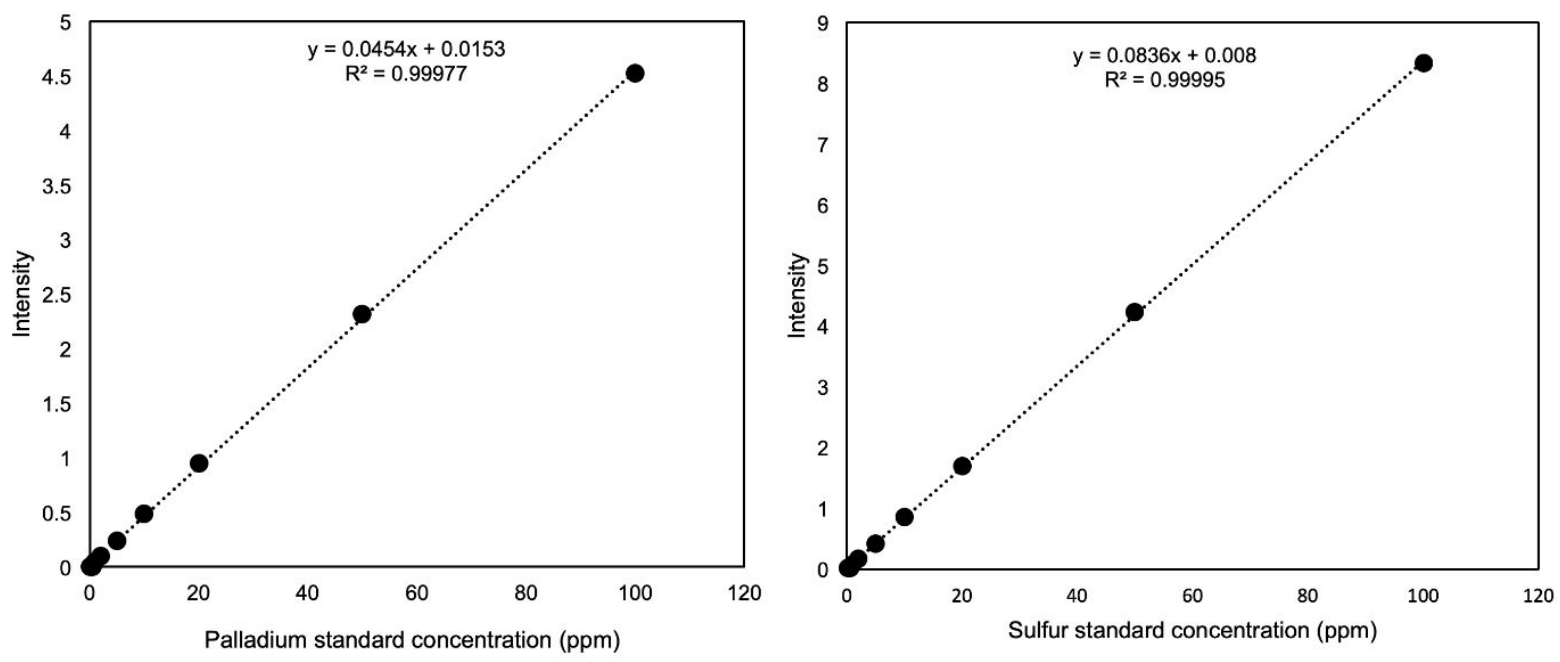

Figure S5. ICP-AES standard curves for palladium and sulfur.

Table S1. Calculation of \% Pd via ICP-AES data.

\begin{tabular}{cccccccccc}
\hline Ligand/Pd & $\begin{array}{c}\text { Average } \\
\text { ICP } \\
\text { Intensity } \\
\text { for Pd }\end{array}$ & $\begin{array}{c}\text { Calculated Pd } \\
\text { Concentration } \\
(\mathrm{ppm})^{\mathrm{a}}\end{array}$ & $\begin{array}{c}\text { Calculated } \\
\text { Pd Mass } \\
\text { from Sample } \\
(\mathrm{mg})^{\mathrm{b}}\end{array}$ & $\begin{array}{c}\text { Average } \\
\text { IItP } \\
\text { Intensity } \\
\text { for S }\end{array}$ & $\begin{array}{c}\text { Calculated S } \\
\text { Concentration } \\
(\mathrm{ppm})^{\mathrm{a}}\end{array}$ & $\begin{array}{c}\text { Calculated S } \\
\text { Mass from } \\
\text { Sample } \\
(\mathrm{mg})^{\mathrm{b}}\end{array}$ & $\begin{array}{c}\text { Calculated } \\
\text { Dodecanethiol } \\
\text { Ligand Mass } \\
\text { from Sample } \\
(\mathrm{mg})^{\mathrm{c}}\end{array}$ & $\begin{array}{c}\text { Mass of } \\
\text { PdNP } \\
\text { Sample } \\
(\mathrm{mg})^{\mathrm{d}}\end{array}$ & $\%$ Pd \\
\hline 4 & 0.3268 & 6.8607 & 1.7152 & 0.08345 & 0.9025 & 0.2256 & 1.4174 & 3.13 & 54.8 \\
2 & 0.3327 & 6.9912 & 1.7478 & 0.06740 & 0.7105 & 0.1776 & 1.1158 & 2.86 & 61.0 \\
1 & 0.5989 & 12.8541 & 3.2135 & 0.10630 & 1.1758 & 0.2940 & 1.8466 & 5.06 & 63.5 \\
0.5 & 0.3859 & 8.1619 & 2.0405 & 0.04640 & 0.4593 & 0.1148 & 0.7214 & 2.76 & 73.9 \\
\hline
\end{tabular}

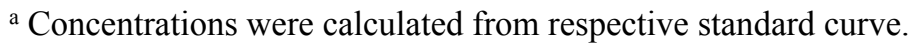

${ }^{\mathrm{b}}$ ICP samples were diluted to $250 \mathrm{~mL}$ with water. Mass of Pd from undiluted sample calculated under this basis.

${ }^{\mathrm{c}}$ Calculated assuming all sulfur corresponds to a dodecanethiol ligand.

d Sum of the calculated mass of Pd and dodecanethiol ligand. 


\section{IV. ${ }^{1} \mathrm{H}$ NMR Analysis of PdNP Catalytic Assays}

a<smiles>CC#CC#CC#CC</smiles>

b

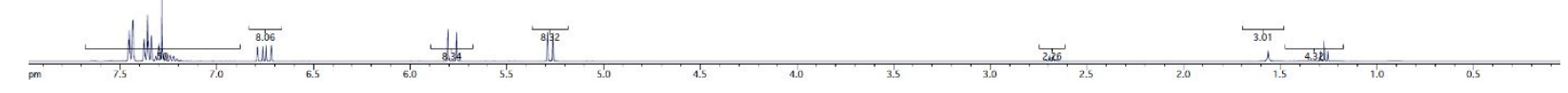

C

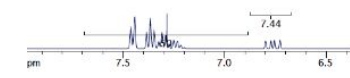

d

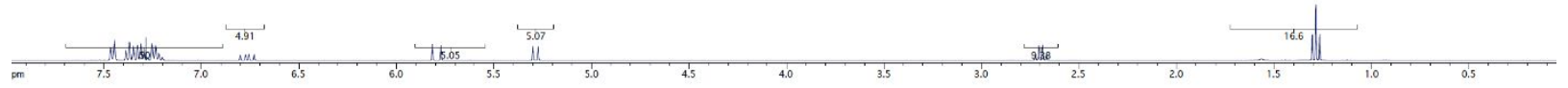

e

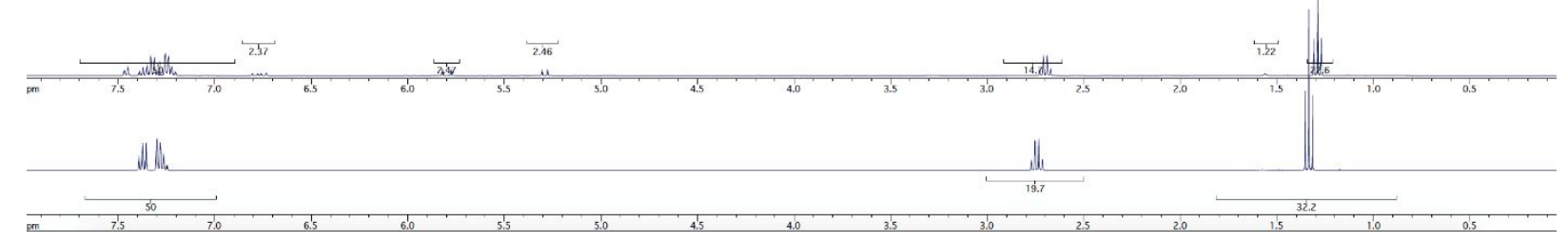

Figure S6. Styrene catalysis with $4 \mathrm{~L} / \mathrm{Pd} \mathrm{PdNP}$. Catalysis reaction times are respectively a) 0.5 hr, b) $1 \mathrm{hr}$, c) 2 hrs, d) $4 \mathrm{hrs}$, e) $6 \mathrm{hrs}$, f) $24 \mathrm{hrs}$.

a

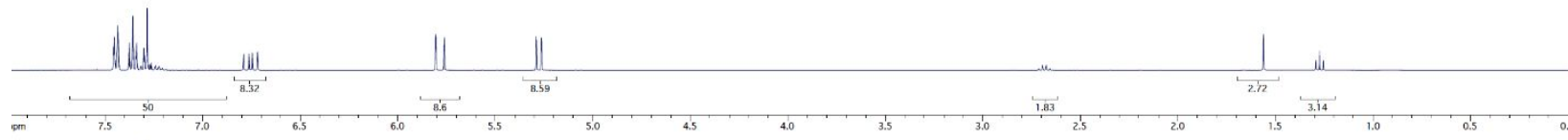

b

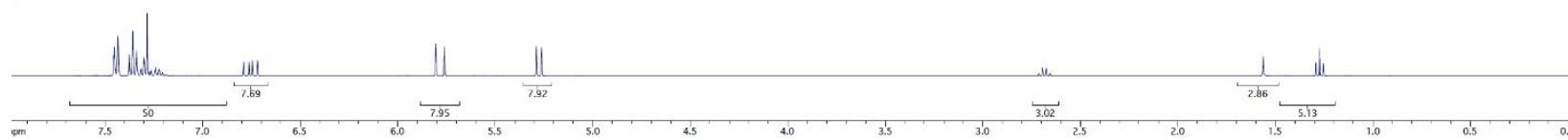

c

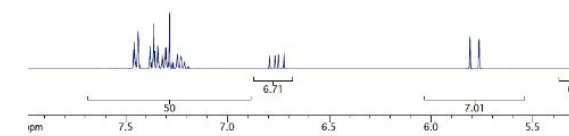

d

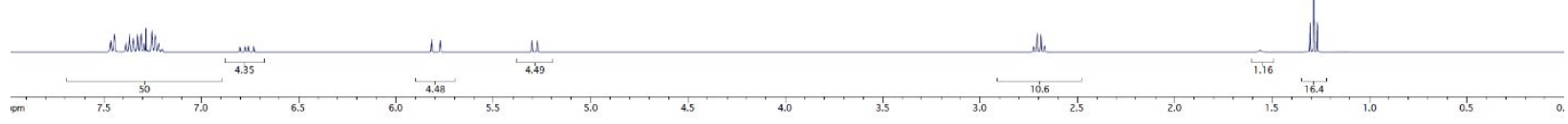

e

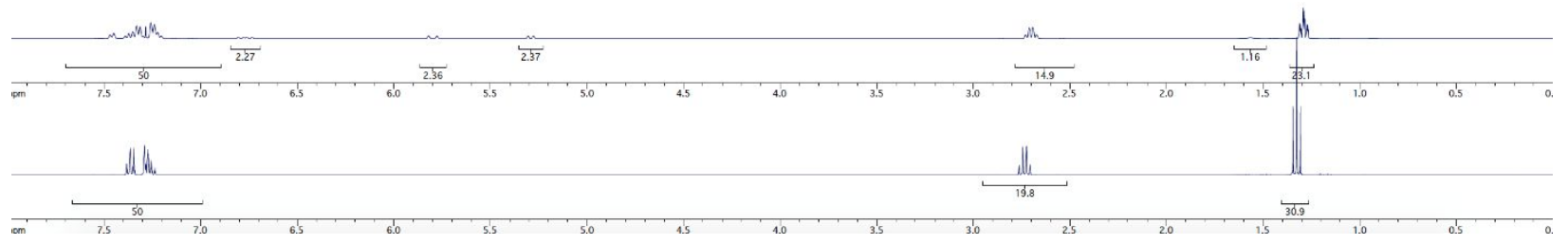

Figure S7. Styrene catalysis with $2 \mathrm{~L} / \mathrm{Pd} \mathrm{PdNP}$. Catalysis reaction times are respectively a) 0.5 hr, b) $1 \mathrm{hr}, \mathrm{c}) 2 \mathrm{hrs}, \mathrm{d}) 4 \mathrm{hrs}$, e) $6 \mathrm{hrs}$, f) $24 \mathrm{hrs}$. 


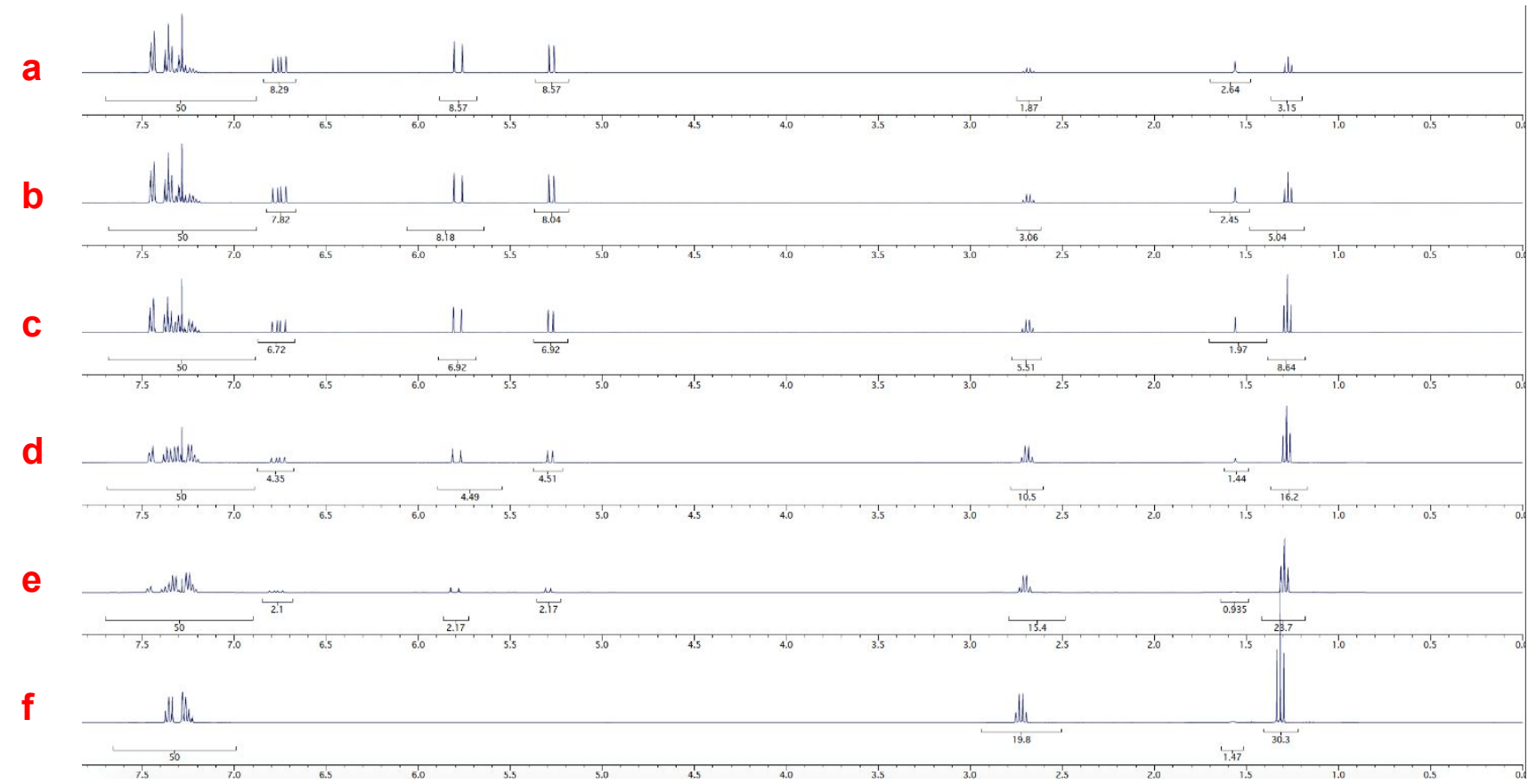

Figure S8. Styrene catalysis with $1 \mathrm{~L} / \mathrm{Pd} \mathrm{PdNP}$. Catalysis reaction times are respectively a) 0.5 hr, b) $1 \mathrm{hr}$, c) $2 \mathrm{hrs}$, d) $4 \mathrm{hrs}$, e) $6 \mathrm{hrs}$, f) $24 \mathrm{hrs}$.

a

a Hum

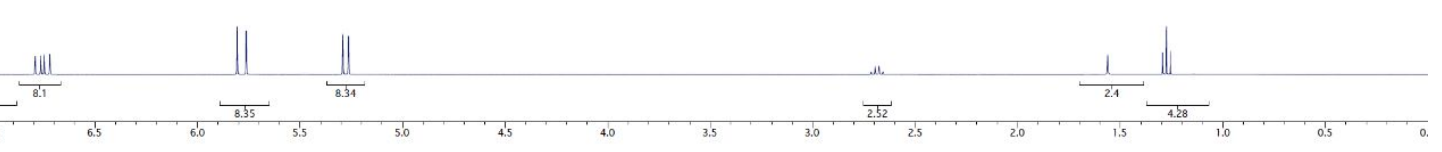

b

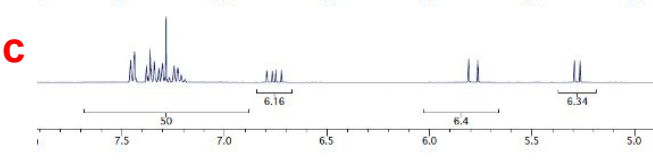

d
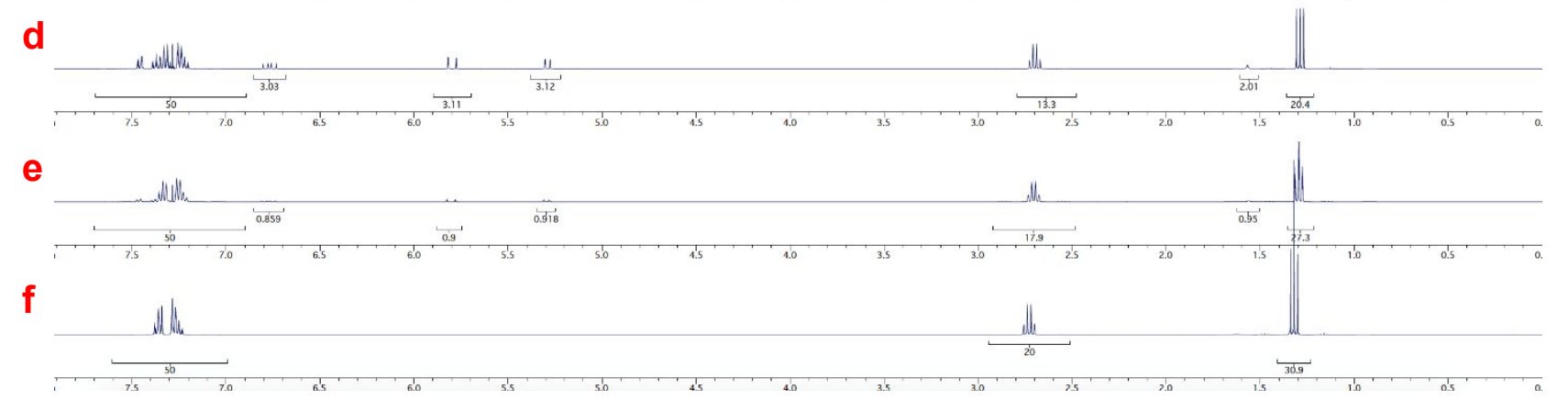

Figure S9. Styrene catalysis with $0.5 \mathrm{~L} / \mathrm{Pd} \mathrm{PdNP}$. Catalysis reaction times are respectively a) 0.5 hr, b) $1 \mathrm{hr}$, c) $2 \mathrm{hrs}$, d) $4 \mathrm{hrs}$, e) $6 \mathrm{hrs}$, f) $24 \mathrm{hrs}$. 


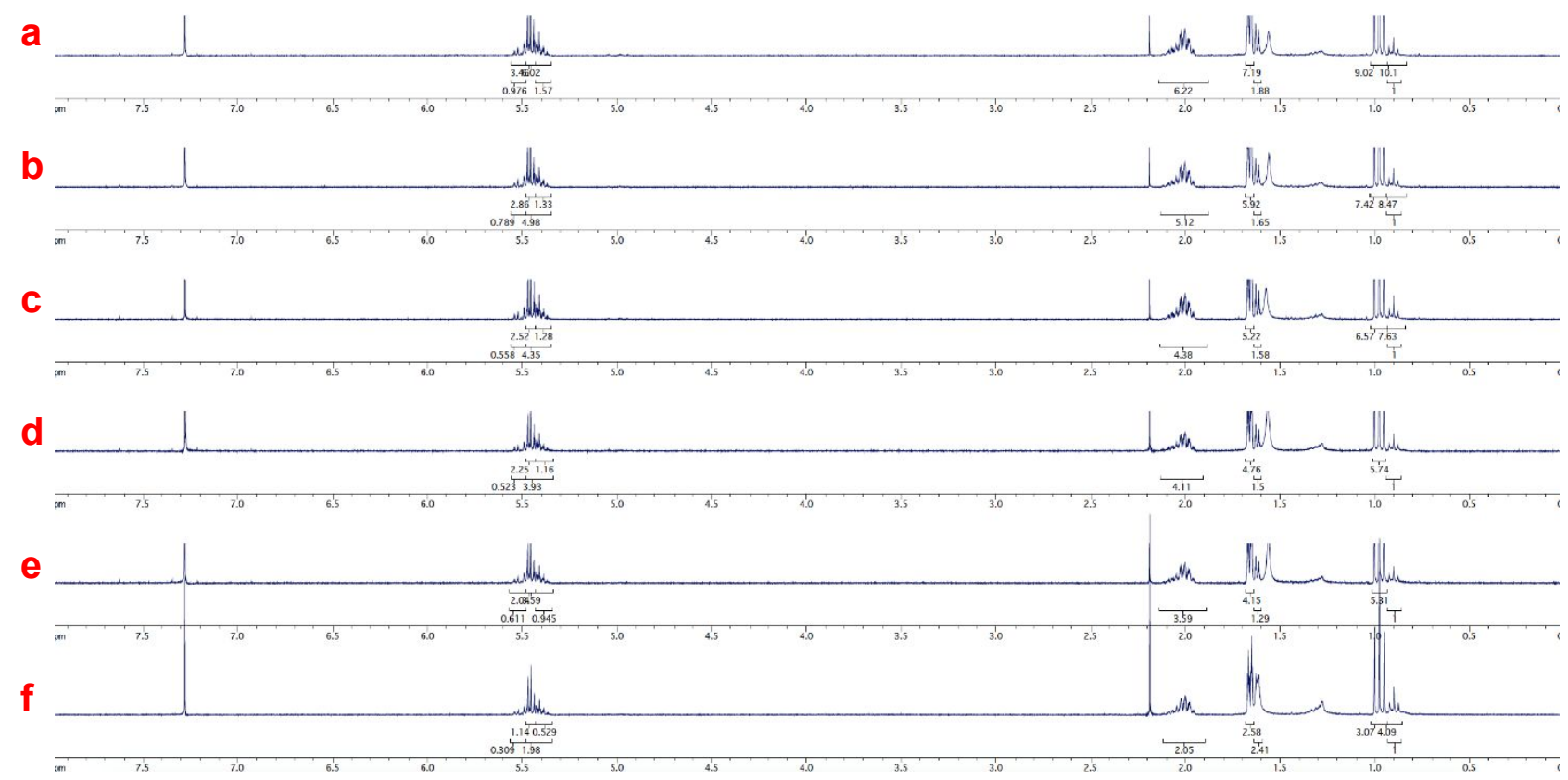

Figure S10. Pent-1-ene catalysis with $4 \mathrm{~L} / \mathrm{Pd} \mathrm{PdNP}$. Catalysis reaction times are respectively a) $0.5 \mathrm{hr}, \mathrm{b}) 1 \mathrm{hr}, \mathrm{c}) 2 \mathrm{hrs}, \mathrm{d}) 4 \mathrm{hrs}$, e) $6 \mathrm{hrs}, \mathrm{f}) 24 \mathrm{hrs}$.

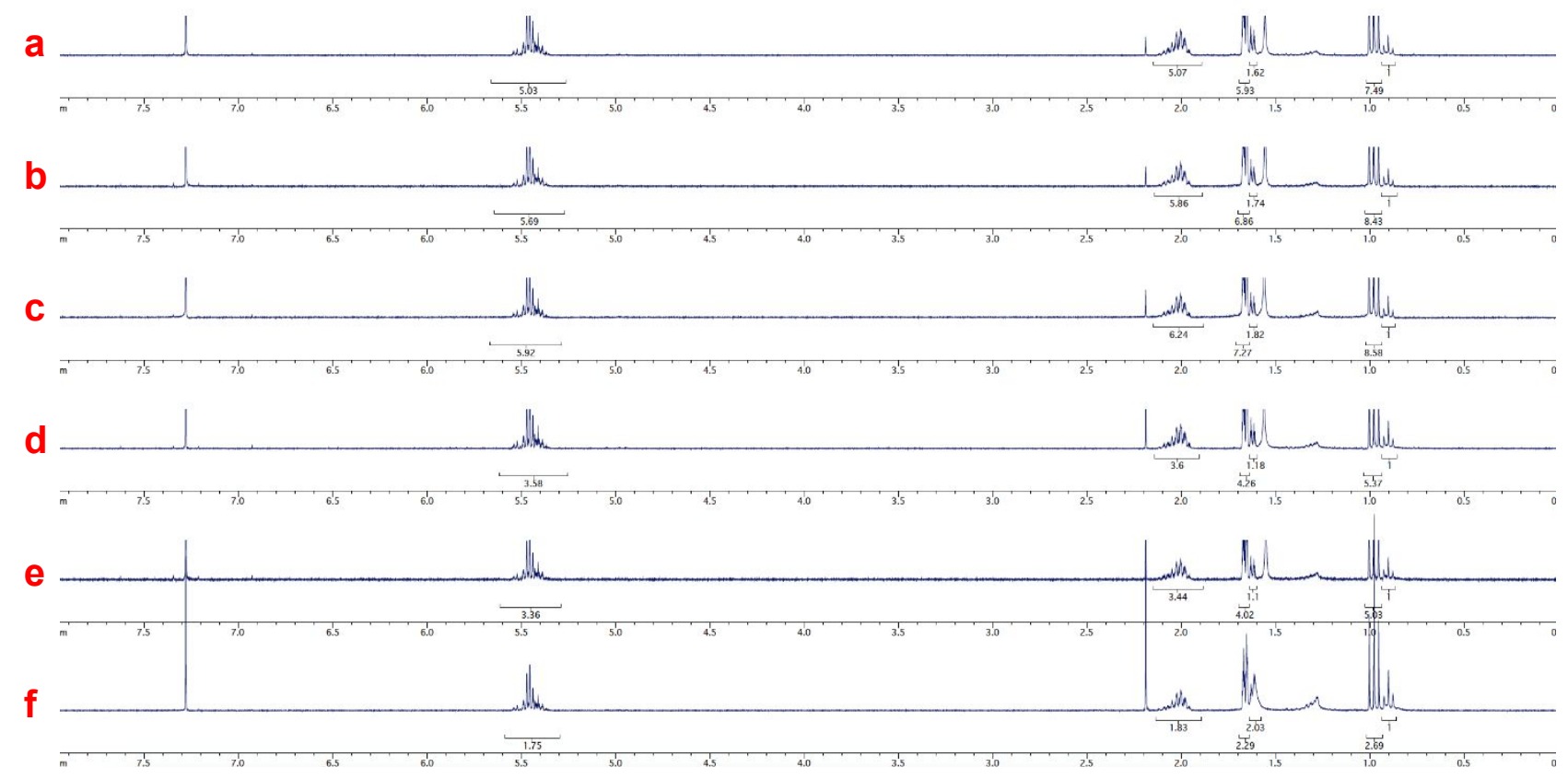

Figure S11. Pent-1-ene catalysis with $2 \mathrm{~L} / \mathrm{Pd} \mathrm{PdNP}$. Catalysis reaction times are respectively a) $0.5 \mathrm{hr}, \mathrm{b}) 1 \mathrm{hr}, \mathrm{c}) 2 \mathrm{hrs}, \mathrm{d}) 4 \mathrm{hrs}$, e) $6 \mathrm{hrs}, \mathrm{f}) 24 \mathrm{hrs}$. 


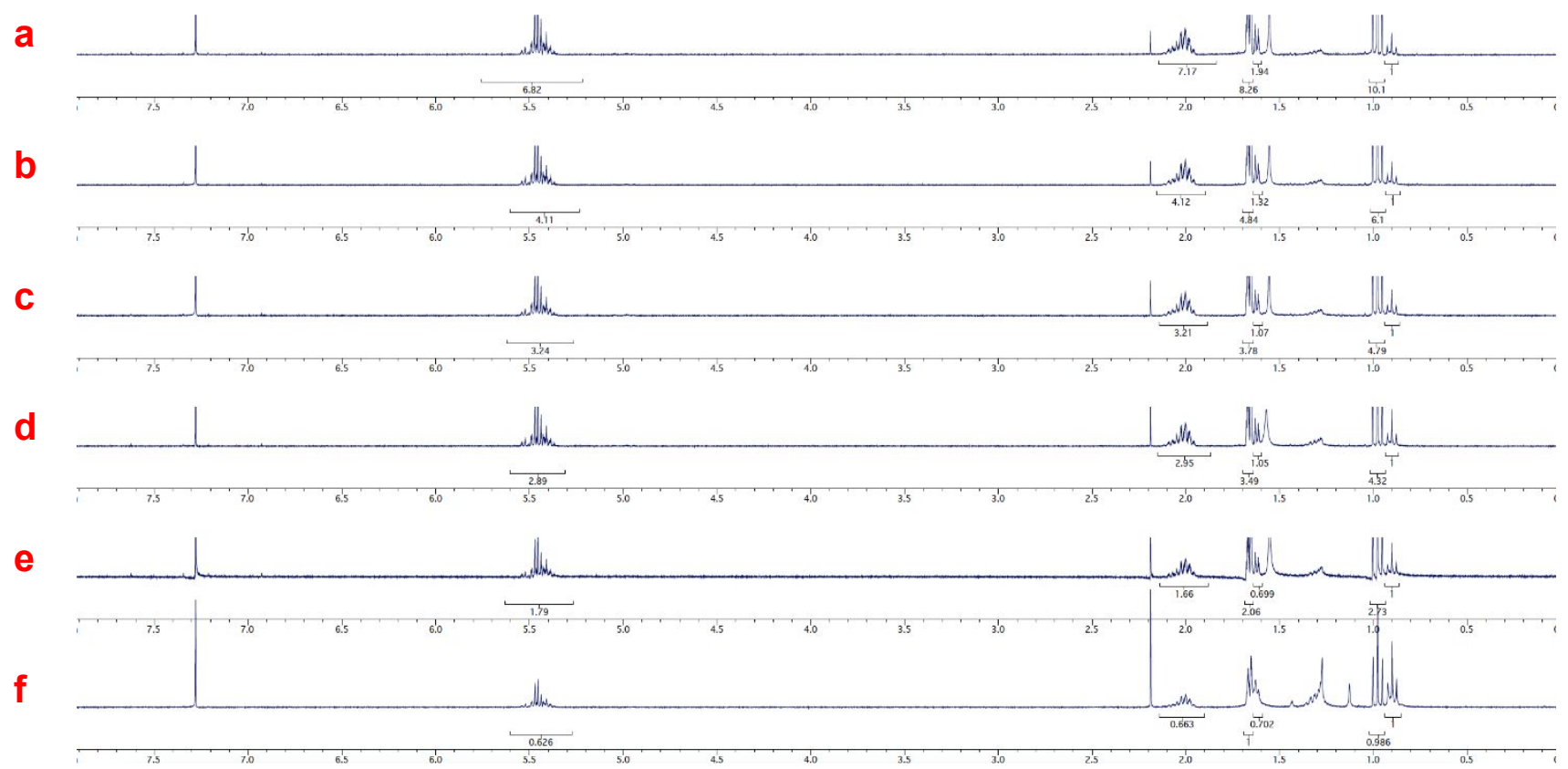

Figure S12. Pent-1-ene catalysis with $1 \mathrm{~L} / \mathrm{Pd} \mathrm{PdNP}$. Catalysis reaction times are respectively a) $0.5 \mathrm{hr}, \mathrm{b}) 1 \mathrm{hr}, \mathrm{c}) 2 \mathrm{hrs}, \mathrm{d}) 4 \mathrm{hrs}$, e) $6 \mathrm{hrs}, \mathrm{f}) 24 \mathrm{hrs}$.

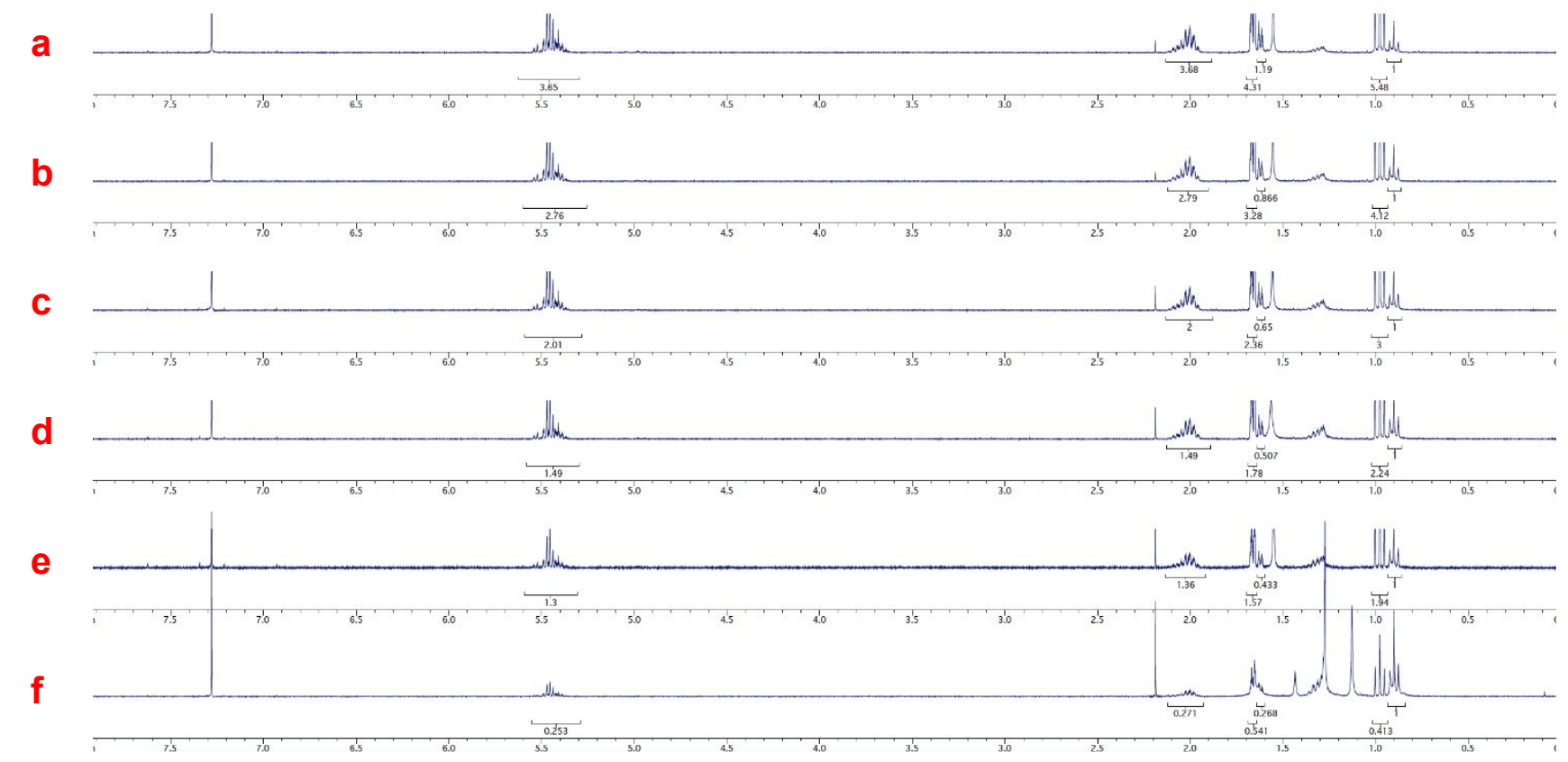

Figure S13. Pent-1-ene catalysis with $0.5 \mathrm{~L} / \mathrm{Pd} \mathrm{PdNP}$. Catalysis reaction times are respectively a) $0.5 \mathrm{hr}, \mathrm{b}) 1 \mathrm{hr}$, c) $2 \mathrm{hrs}$, d) $4 \mathrm{hrs}$, e) $6 \mathrm{hrs}, \mathrm{f}) 24 \mathrm{hrs}$. 


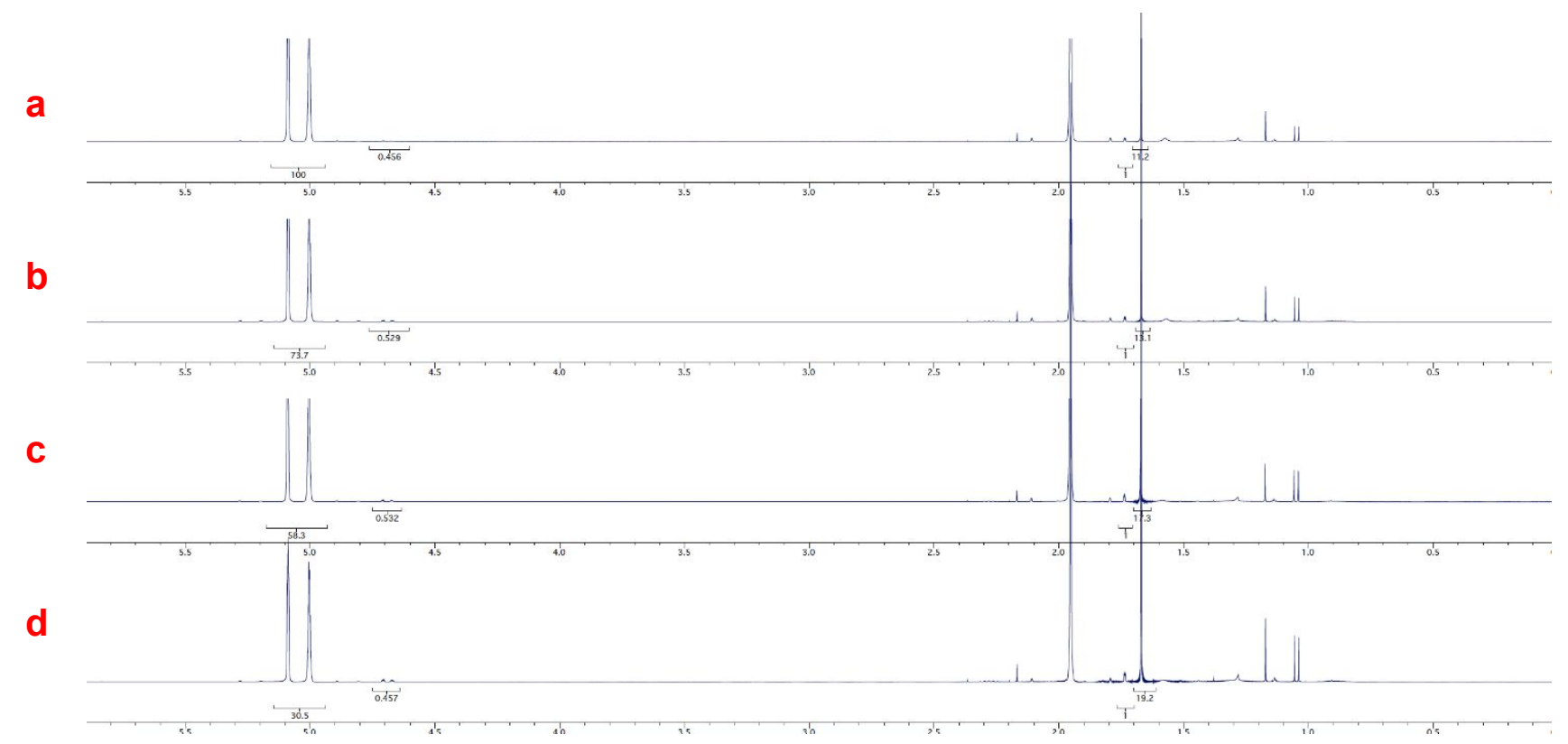

Figure S14. 2,3-Dimethylbuta-1,3-diene catalysis with $4 \mathrm{~L} / \mathrm{Pd} \mathrm{PdNP}$. Catalysis reaction times are respectively a) $0.5 \mathrm{hr}$, b) $1 \mathrm{hr}$, c) $2 \mathrm{hrs}$, d) $4 \mathrm{hrs}$.

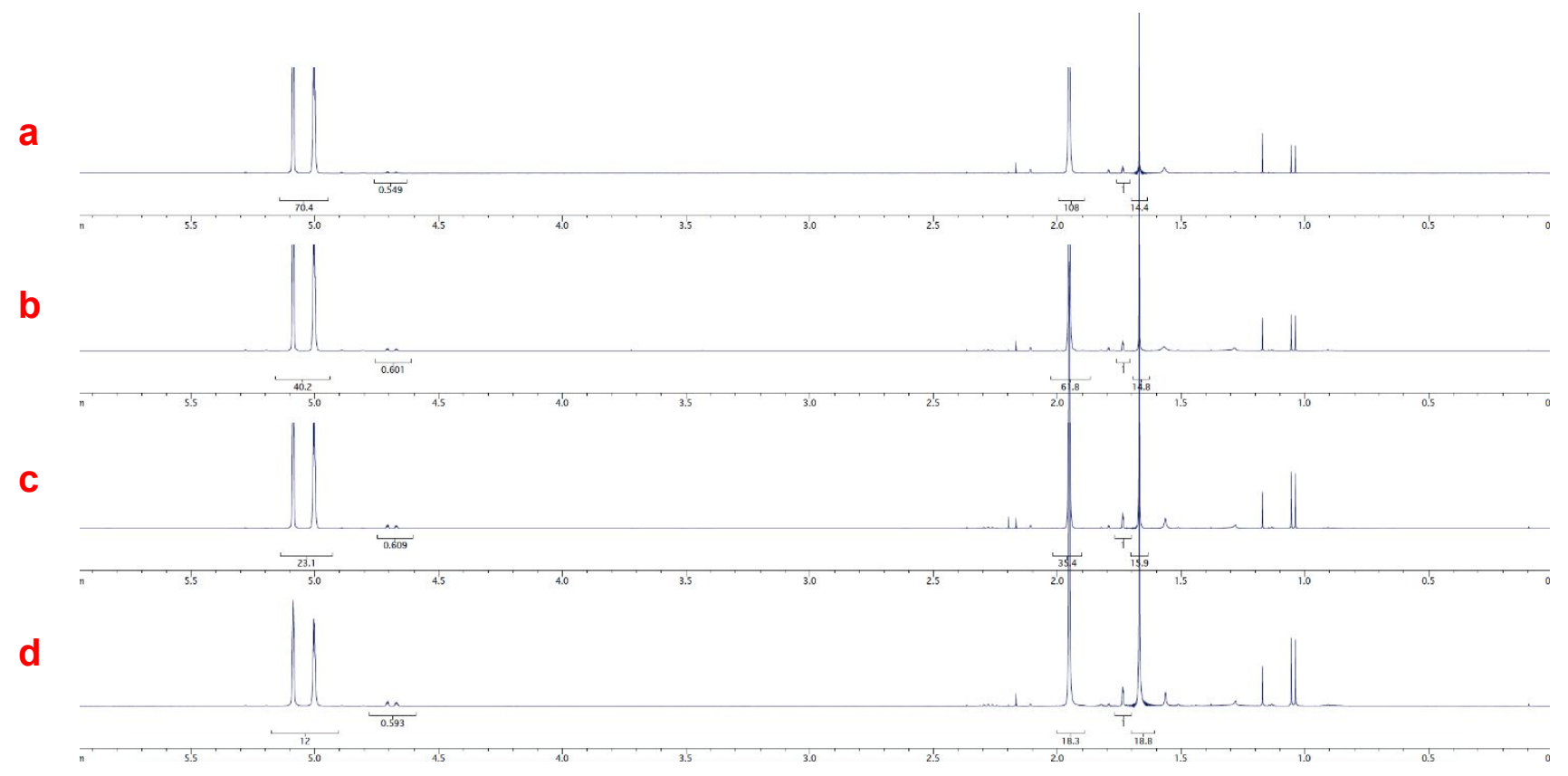

Figure S15. 2,3-Dimethylbuta-1,3-diene catalysis with $2 \mathrm{~L} / \mathrm{Pd} \mathrm{PdNP}$. Catalysis reaction times are respectively a) $0.5 \mathrm{hr}, \mathrm{b}) 1 \mathrm{hr}$, c) $2 \mathrm{hrs}$, d) $4 \mathrm{hrs}$. 


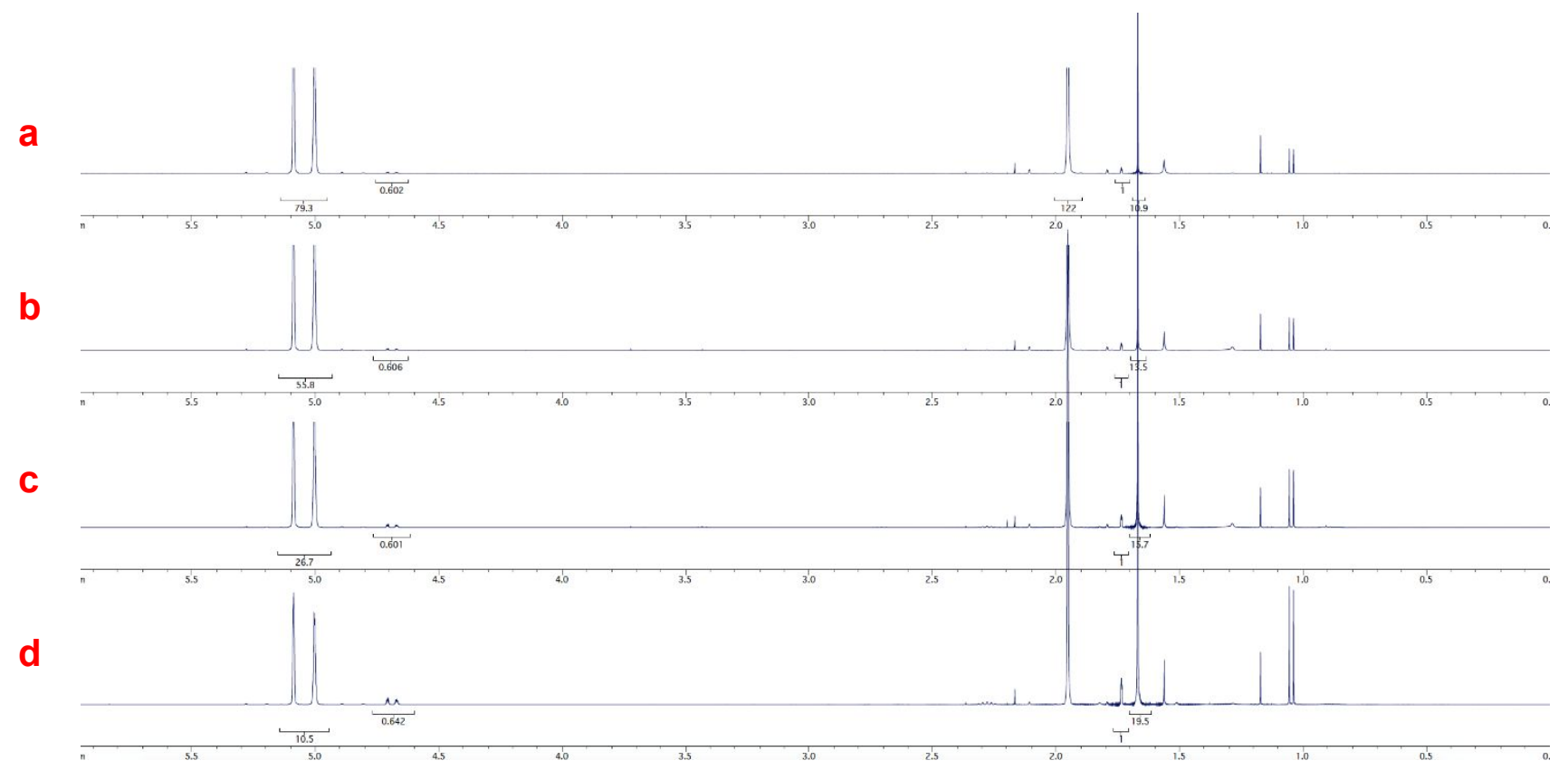

Figure S16. 2,3-Dimethylbuta-1,3-diene catalysis with $1 \mathrm{~L} / \mathrm{Pd} \mathrm{PdNP}$. Catalysis reaction times are respectively a) $0.5 \mathrm{hr}$, b) $1 \mathrm{hr}$, c) $2 \mathrm{hrs}$, d) $4 \mathrm{hrs}$.

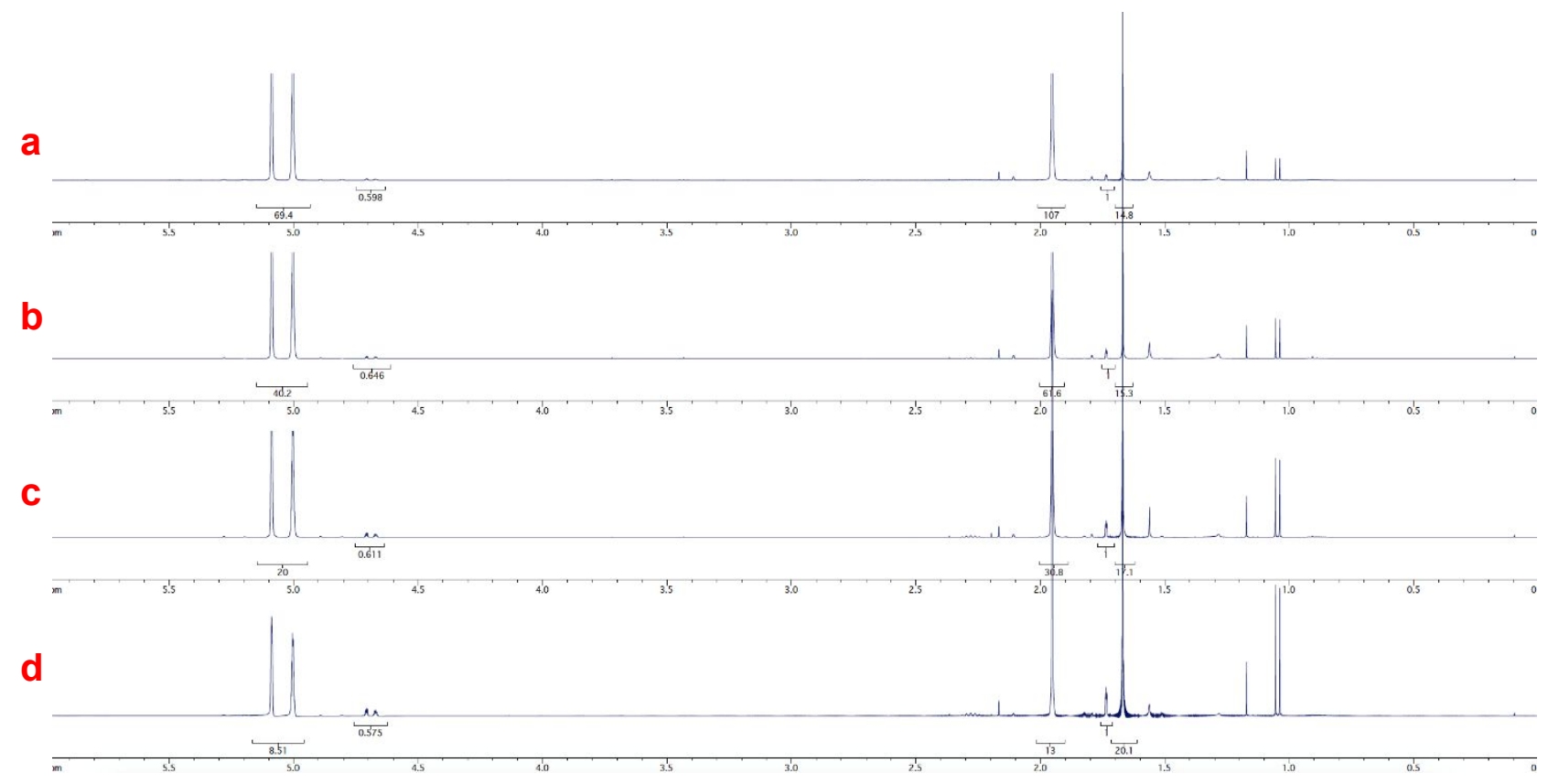

Figure S17. 2,3-Dimethylbuta-1,3-diene catalysis with 0.5 L/Pd PdNP. Catalysis reaction times are respectively a) $0.5 \mathrm{hr}$, b) $1 \mathrm{hr}$, c) $2 \mathrm{hrs}$, d) $4 \mathrm{hrs}$. 


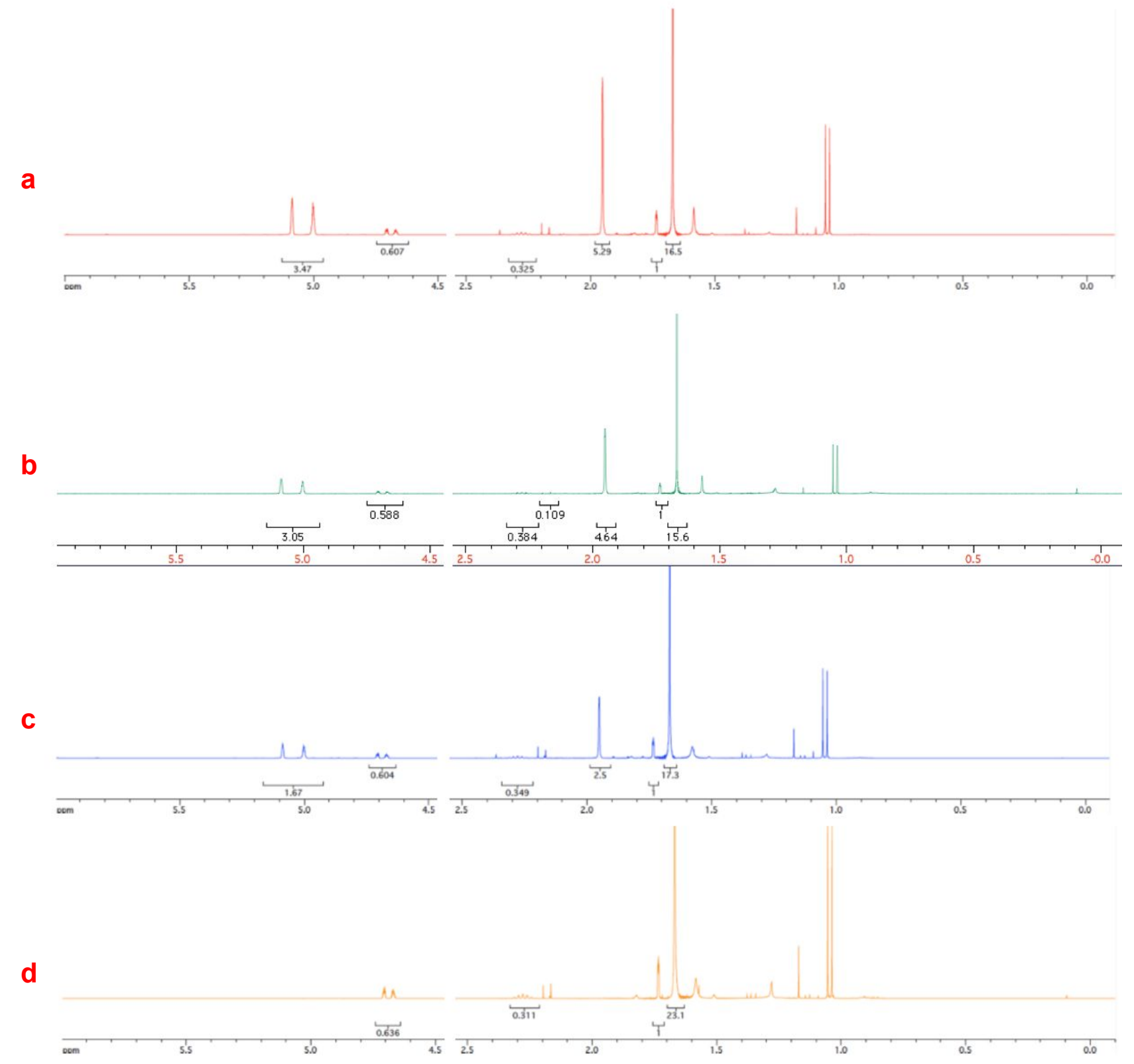

Figure S18. 2,3-Dimethylbuta-1,3-diene $24 \mathrm{hr}$ catalysis with 4, 2, 1, $0.5 \mathrm{Pd} / \mathrm{L} \mathrm{PdNP}$ respectively. 


\section{Catalytic Conversion Graphs}

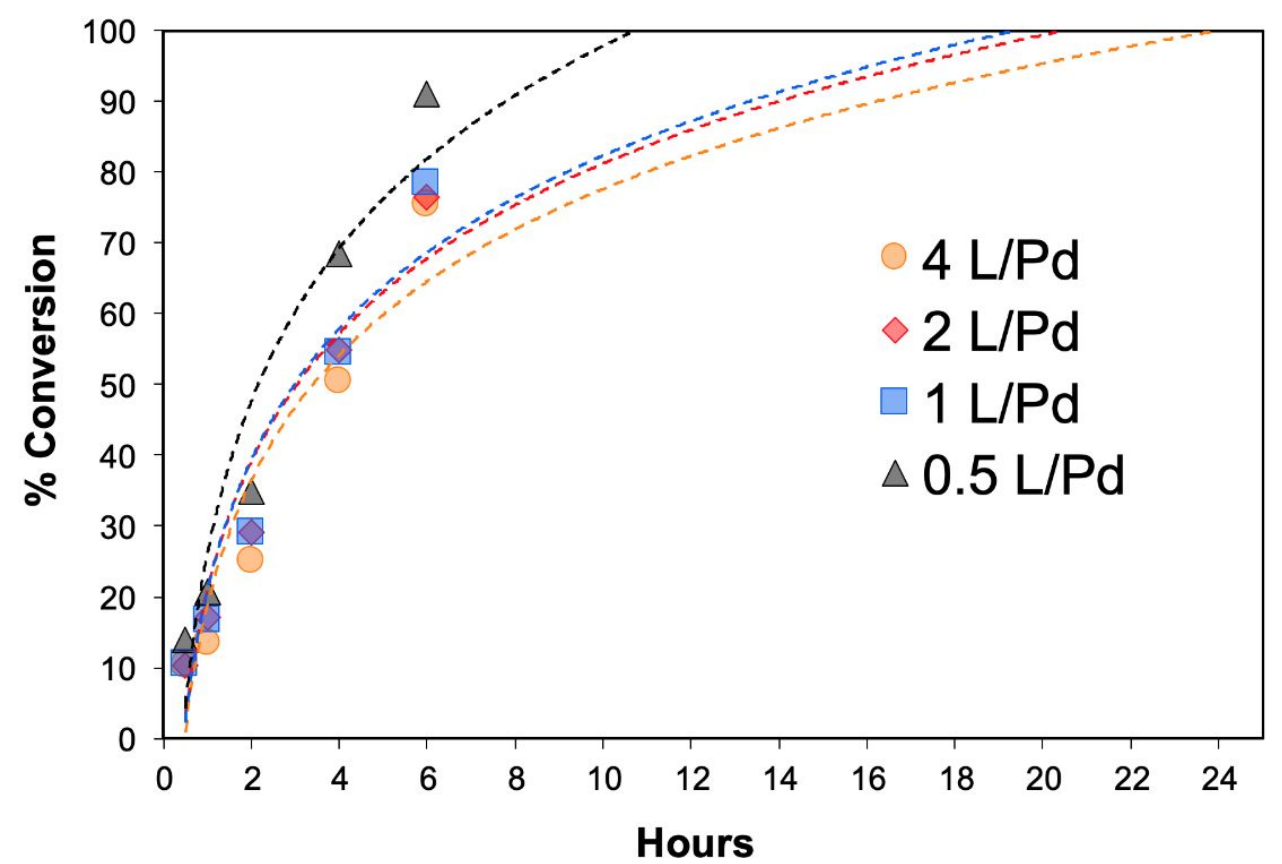

Figure S19. Catalytic conversion of the hydrogenation of styrene with PdNP catalysts. Graphs are fitted based on conversion data from 0 to $6 \mathrm{~h}$. Beyond 6 hours are extrapolations of the curves.

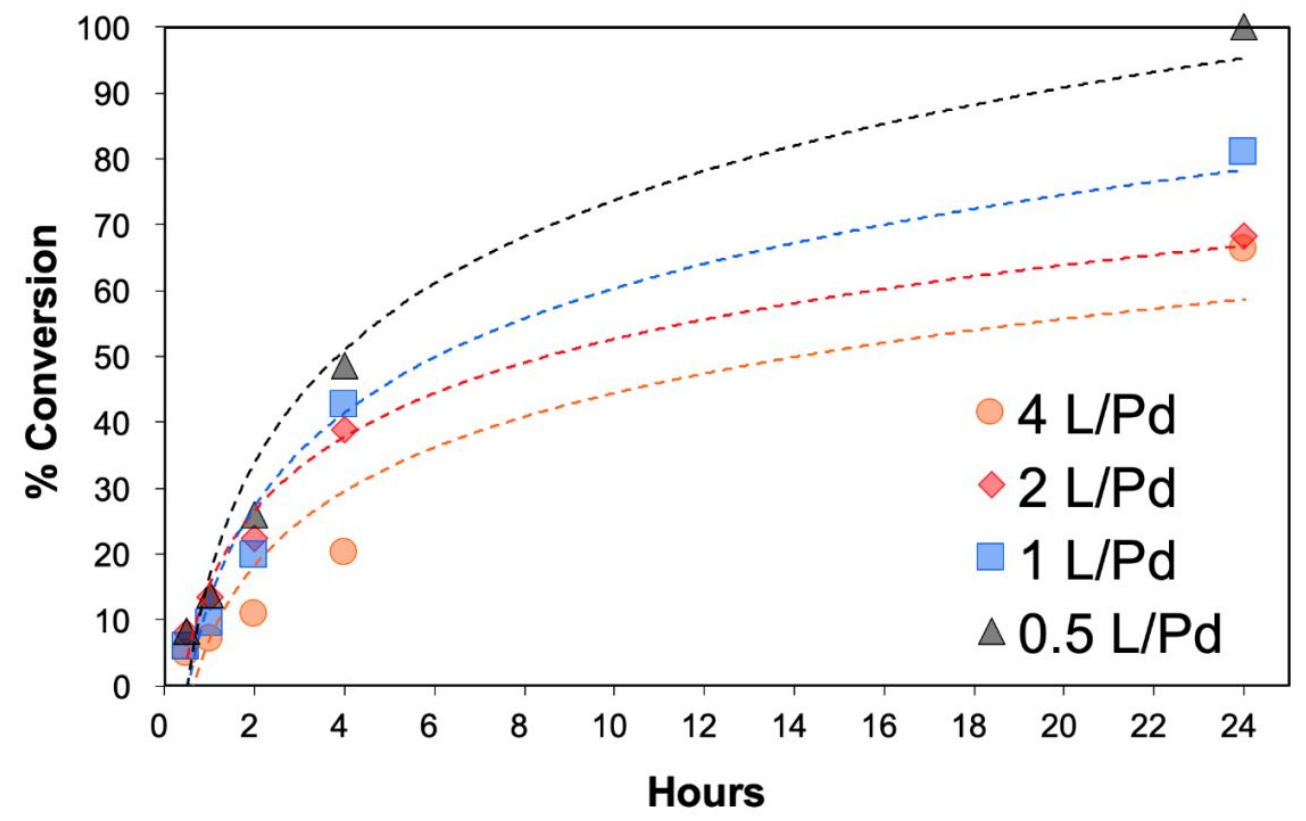

Figure S20. Catalytic Conversion for PdNP catalyzed 1,2-addition vs 1,4-addition of 2,3dimethylbuta-1,3-diene. 


\section{Fractionation Data}

$\begin{array}{ccc}\text { L/Pd } & \begin{array}{c}\text { TEM (diameter, } \\ \text { nm) }\end{array} & \text { \% Conversion } \\ 4 & 2.5 \pm 0.7 & 22.7 \% \\ 2 & 2.4 \pm 0.7 & 29.7 \% \\ 1 & 2.5 \pm 0.9 & 58.9 \% \\ 0.5 & 2.5 \pm 0.9 & 71.5 \% \\ \text { Catalysis conducted under conditions earlier described over the course of } 3 \text { hours. }\end{array}$

Table S2. Fractionation of PdNPs and catalysis with styrene

Fractionation Experiments. PdNPs synthesized via reversed alkyl thiosulfate addition were subjected to a series of fractionations with increasing amounts of antisolvent. In $15 \mathrm{~mL}$ conical mcentrifuge tubes (Falcon), about $30 \mathrm{mg}$ of each of the four PdNP samples were dissolved in 2 $\mathrm{mL}$ of chloroform. The samples were then centrifuged at 10,000 rpm for 10 minutes. Following centrifugation, the supernatant of each sample was transferred to a new centrifuge tubes and the pelleted PdNPs were stored under vacuum. To the centrifuge tubes containing the supernatant, $0.5 \mathrm{~mL}$ of methanol antisolvent ( $20 \%$ antisolvent) was added. This process was repeated with increasing amounts of antisolvent $(40 \%, 60 \%, 80 \%, 90 \%)$, collecting the precipitated PdNP in each fraction. The precipitated PdNPs from the $80 \%$ antisolvent fraction were characterized via TEM and size distribution analysis. These isolated PdNPs were assayed for the catalytic hydrogenation of styrene (3-hour reaction time) using the procedure and conditions described in previous section on catalytic assays. 


\section{Recycle Study Data}

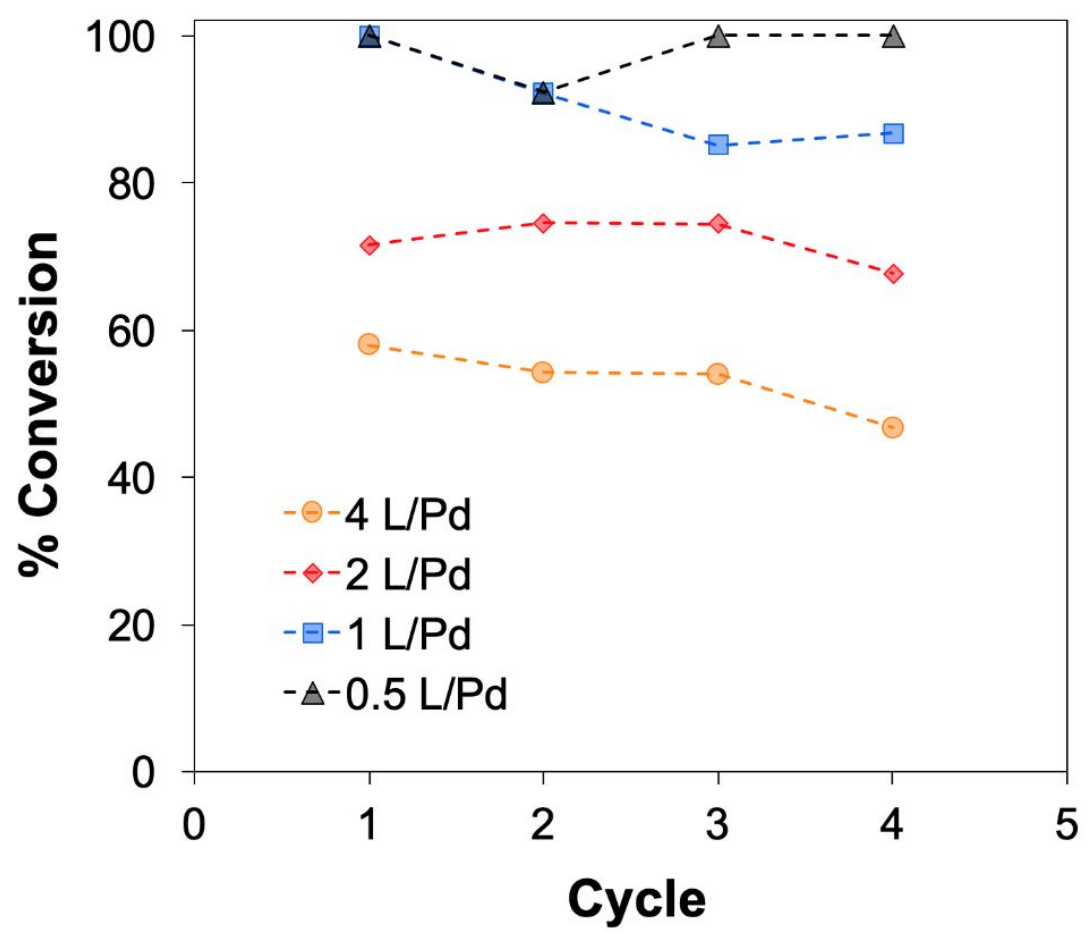

Figure S21. Recycle study of PdNPs with varying surface ligand density. (4-hour reaction at room temperature using $0.25 \mathrm{mmol}$ of substrate and $5 \mathrm{~mol} \%$ of PdNPs in $2 \mathrm{~mL}$ of $\mathrm{CDCl}_{3}$ ) 